\title{
Preliminary assessment of the potential role of urbanization in the distribution of carbamate and organophosphate resistant populations of Culex species in Ghana
}

Andreas A Kudom ${ }^{1,2^{*}}$, Ben A Mensah², Guenter Froeschl' ${ }^{1}$, Daniel Boakye ${ }^{3}$ and Heinz Rinder ${ }^{1,4}$

\begin{abstract}
Background: Besides its role as a pathogen vector, Culex species also indirectly promotes the transmission of malaria if the use of bed nets or indoor residual spraying is discontinued due to a lack of insecticide efficacy against it. A recent survey revealed widespread occurrence of pyrethroid resistance among urban populations of this mosquito in Ghana. In order to plan and implement insecticide-based resistance management strategies, this study was carried out to assess resistance status of Culex species to organophosphate and carbamate in urban areas in Ghana and the possible mechanisms involved as well as environmental factors associated with its distribution.

Methods: Mosquito larvae were sampled from various land use and ecological settings and in different seasons. In adults, susceptibility to organophosphates (fenitrothion, malathion) and carbamates (propoxur, bendiocarb) were determined. Mixed function oxidase (MFO) and $\alpha$ - and $\beta$-esterase assays, as well as a PCR diagnostic assay to determine ace 1 mutation were performed in individual mosquitoes.

Results: Culex quinquefasciatus as well as C. decens and other unidentified Culex species were found breeding in polluted water bodies in the study sites. Across all sites and seasons, carbamate induced mortality was $94.1 \% \pm 15.4$ whereas mortality caused by organophosphate was $99.5 \% \pm 2.2$. In addition, ace 1 mutation and high levels of esterases were detected in some of the mosquito populations. There was a strong correlation between susceptibility status of the mosquitoes and the level of absorbance of $\beta$-esterase (Pearson $r=-0.841, p=0.004$ ).

Conclusions: The study found low prevalence of resistance to carbamate and organophosphate insecticides among Culex species from Ghana. However, there were populations with ace1 mutations and high levels of esterases, which can confer high resistance to these classes of insecticides. Thus, it is important to monitor activities or behaviour that has the potential to select for carbamate and organophosphate resistance populations.
\end{abstract}

Keywords: ace1, Carbamate, Culex decens, Culex quinquefasciatus, Ecology, Esterase, Organophosphate, Insecticide-resistance, Urbanization

\footnotetext{
* Correspondence: akudom@ucc.edu.gh

${ }^{1}$ Center for International Health, Department of Infectious Diseases and

Tropical Medicine, Ludwig-Maximilians-Universität Munich, Munich, Germany

${ }^{2}$ Department of Entomology and Wildlife, School of Biological Sciences,

University of Cape Coast, Cape Coast, Ghana

Full list of author information is available at the end of the article
} 


\section{Background}

Recommended options for malaria control include the use of long-lasting insecticide-treated bed nets (LLIN) and indoor residual spraying (IRS) [1]. Unfortunately, LLIN is highly dependent on a single class of insecticides, the pyrethroids, for which malaria vectors and other mosquitoes have developed resistance. In order to act before insecticide resistance compromises current vector control strategies, WHO has proposed various guidelines to encourage countries to plan and implement insecticide resistance management strategies [2].

Successful resistance management depends upon reducing the selection pressure exerted by a particular insecticide or a particular mode of action [3]. Four classes of insecticides, namely pyrethroids, organochlorine (exclusively DDT), organophosphates and carbamates are used widely in the public health sector; however, pyrethroids and DDT share similar modes of action, thus making organophosphate and carbamate very important in resistance management strategies. Various resistance management strategies including rotations, mosaics and mixture of pyrethroid and/or organophosphate or carbamate for IRS and on nets have been demonstrated both in laboratory and field conditions $[4,5]$. As a result, knowledge on resistance status of vectors against organophosphate or carbamate and the mechanism involved as well as factors that influence the resistance have become important.

Until recently, most research efforts on insecticide resistance in mosquitoes have been focused on determining the mosquitoes' resistance status and the mechanisms responsible. Less attention has been paid to the impact of environmental factors that can influence resistance in mosquitoes. Recent studies have found pollutants in urban water bodies, which are mostly generated by motor vehicles, industries and domestic waste, to affect mosquito detoxification enzymes leading to enhanced insecticide degradation [6]. Several studies in Ghana have shown different levels of susceptibility to organophosphates and carbamates in Anopheles mosquitoes including the presence of ace 1 mutation in some populations [7-9]. However, for Culex species, which also plays a critical role in malaria control, information on susceptibility to organophosphate and carbamate is limited. Besides its role as a pathogen vector itself, Culex species also indirectly promotes the transmission of malaria, if the use of bed nets or IRS is discontinued due to a lack of insecticide efficacy against it. A recent survey revealed widespread occurrence of pyrethroid resistance among urban populations of this mosquito in Ghana (Kudom et al. unpublished observations.). This study was therefore carried out to assess resistance status of Culex species to organophosphate and carbamate in urban areas in Ghana and the possible mechanisms involved as well as environmental factors associated with its distribution.

\section{Methods}

\section{Study sites}

Mosquito larvae were collected from ponds, polluted drains and choked gutters in nine urban areas in Ghana (Figure 1). Urban areas were selected according to ecological settings and in each selected town, mosquitoes were sampled from different land use settings; residential, urban agricultural and swampy areas. Mosquito larvae were also sampled in both rainy and dry seasons. Larvae were brought to the laboratory for emergence and testing of adults.

\section{Susceptibility test}

An adult susceptibility assay was carried out using WHO discriminating dosages of two insecticides each from organophosphate (Fenitrothion 1\%, Malathion 5\%) and carbamate (Bendiocarb 0.1\%, Propoxur 0.1\%). Mosquitoes were exposed to the insecticides according to WHO guidelines (WHO/VBC/81.806). Mortality resulting from tarsal contact with treated filter paper was measured using WHO test kits. Four batches of 20-25 unfed females, aged 2-4 days, were exposed to papers impregnated with malathion or bendiocarb for $1 \mathrm{~h}$, fenitrothion or propoxur for $2 \mathrm{~h}$.

\section{Biochemical assay}

Mixed function oxidase (MFO) and $\alpha$ - and $\beta$-esterase were assayed in individual $2-4$ day old frozen $\left(-80^{\circ} \mathrm{C}\right)$ adults that had been reared from larvae and not been previously exposed to insecticides in the laboratory. The procedures in preparing the solutions and conducting the experiments followed the method described by Hemingway [10]. A total of about 450 mosquitoes, comprising fifty female individuals from each of the nine study sites were used for the biochemical assay. Mosquitoes were homogenized in potassium phosphate buffer ( $\mathrm{pH}$ 7.2) and the homogenate was loaded into micro plate wells in duplicate on the same plate for each enzyme assay. A plate-reading spectrophotometer was used to collect data at the appropriate absorbing wavelength (nm).

For the esterase assay, $100 \mu \mathrm{l}$ mosquito homogenate with $100 \mu \mathrm{l} \alpha$ - or $\beta$-naphthyl acetate was incubated at room temperature for 10 minutes. Then, $100 \mu \mathrm{l}$ dianisidine solution was added to the mixture and incubated for 2 minutes. The plate was then read using a $620 \mathrm{~nm}$ filter for $\alpha$-naphthyl and $540 \mathrm{~nm}$ filter for $\beta$-naphthyl.

For the oxidase assay, $100 \mu \mathrm{l}$ mosquito homogenate with $200 \mu \mathrm{l}$ of Tetramethyl-Benzidine and $25 \mu \mathrm{l}$ of $3 \%$ hydrogen peroxide were incubated for 5 minutes. The plate was then read using a $620 \mathrm{~nm}$ filter.

\section{Species identification and detection of ace 1 mutations}

Genomic DNA was extracted from 20 mosquitoes each from the nine urban sites. These mosquitoes had not been previously exposed to insecticide. The DNA was 


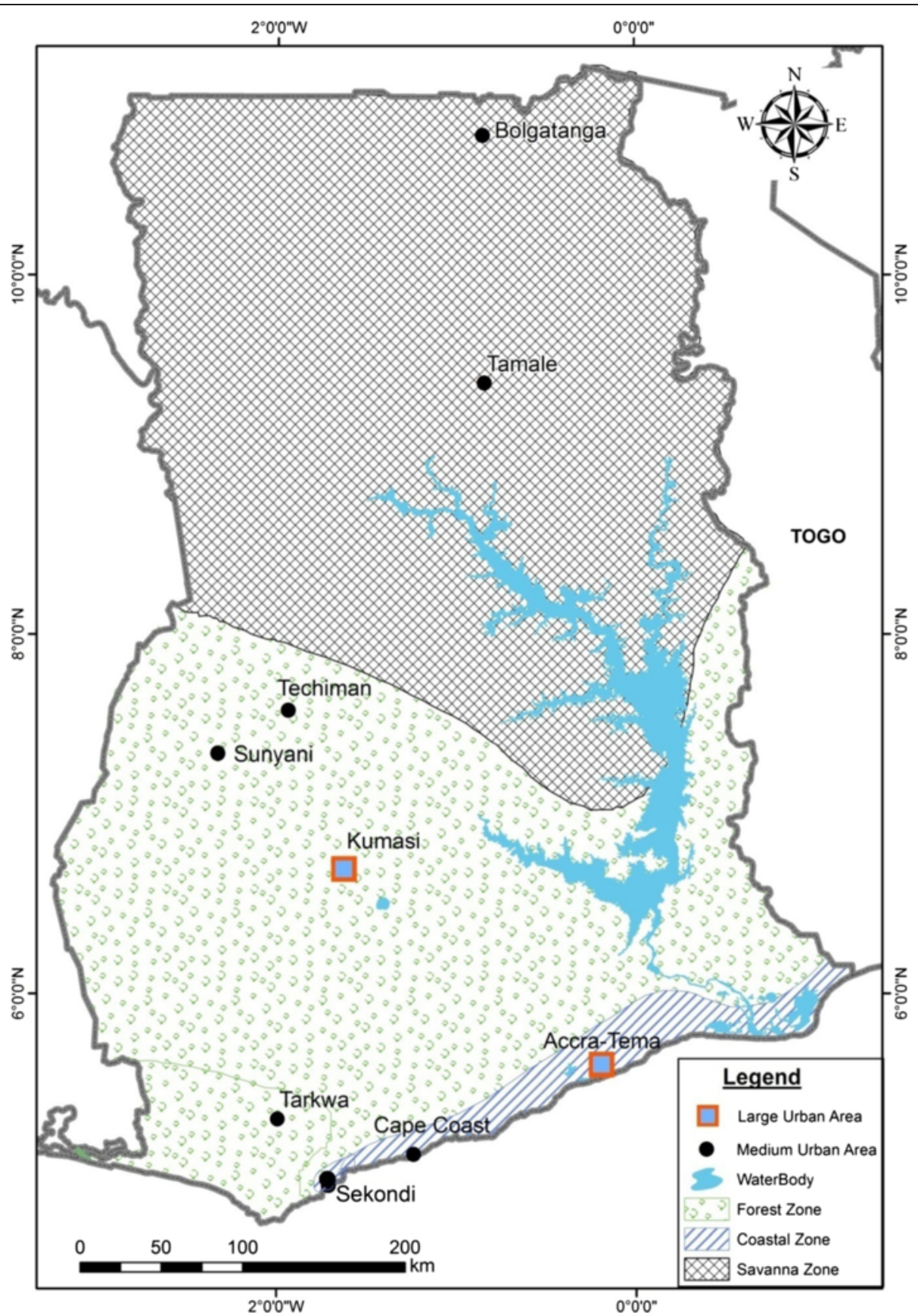

Figure 1 Map of Ghana showing the three ecological zones and urban towns where mosquitoes were sampled.

extracted with DNeasy extraction kit (QIAGEN) based on the protocol from the manufacturer.

Mosquitoes for this study were mostly collected from polluted water bodies; hence C. quinquefasciatus was generally expected. PCR diagnostic assay was therefore carried out to identify $C$. quinquefasciatus using the method described by Smith and Fonseca [11]. Four primers ("ACEquin”,"B1246s", F1457" and "B1246) (Table 1) were used to detect $C$. quinquefasciatus and any other species that belongs to the $C$. pipiens complex.
Also, the universal DNA primers, LCO1490 and HCO2198 (Table 1) of Folmer et al. [12] were used to amplify an 830 bp region of the mitochondrial cytochrome oxidase subunit I gene of four mosquitoes randomly selected from the mosquitoes that failed to amplify from the previous PCR assays.

Based on the results from the sequence, two primers (Cddir and Cdrev) (Table 1) were designed from $C$. decens cytochrome c oxidase subunit 1 (CO1), which was obtained from Genebank with accession number 
Table 1 Oligonucleotides (primers) used for identification of Culex species and detection of ace 1 mutation

\begin{tabular}{ll}
\hline $\begin{array}{l}\text { Type of molecular } \\
\text { assay }\end{array}$ & Primers \\
\hline $\begin{array}{l}\text { Species } \\
\text { identification }\end{array}$ & ACEquin 5'-CCTTCTTGAATGGCTGTGGCA-3' \\
& B1246s 5'-TGGAGCCTCCTCTTCACGG-3' \\
& F1457 5'-GAGGAGATGTGGAATCCCAA-3' \\
& B1246 5'-TGGAGCCTCCTCTTCACGGC-3' \\
& Cddir 5'-ACCTCGACGATACTCCGATTT-3' \\
& Cdrev 5'-TGTGTTCTGCAGGAGGAAGA-3' \\
& LCO1490 5'-GGTCAACAAATCATAAAGATATTGG-3' \\
& HCO2198 5'-TAAACTTCAGGGTGACCAAAAAATCA-3' \\
& Moustdir1 5'-CCGGGNGCSACYATGTGGAA-3' \\
mutation & Moustrev1 5'-ACGATMACGTTCTCYTCCGA-3' \\
\hline
\end{tabular}

AY64524. The primer was designed with Primer $3^{\circ}$ software. PCR was conducted with Cddir and Cdrev on the DNAs that failed to amplify in the previous PCR assay.

Each PCR contained $5 \mathrm{ml}$ of 10 PCR buffer, $1.5 \mathrm{mM}$ of $\mathrm{MgCl}_{2}, 35 \mathrm{ml}$ of distilled water, $200 \mathrm{mM}$ of each dNTP, 1 unit of Taq polymerase, $0.3 \mathrm{mM}$ of each primer and $3 \mu \mathrm{l}$ of DNA template. The PCR thermal condition consisted of one cycle of $1 \mathrm{~min}$ at $94^{\circ} \mathrm{C}$; five cycles of $1 \mathrm{~min}$ at $94^{\circ} \mathrm{C}, 1.5 \mathrm{~min}$ at $45^{\circ} \mathrm{C}$ and $1.5 \mathrm{~min}$ at $72^{\circ} \mathrm{C} ; 35$ cycles of $1 \mathrm{~min}$ at $94^{\circ} \mathrm{C}, 1.5 \mathrm{~min}$ at $50^{\circ} \mathrm{C}$ and $1 \mathrm{~min}$ at $72^{\circ} \mathrm{C}$ and a final cycle of $5 \mathrm{~min}$ at $72^{\circ} \mathrm{C}$. To confirm a successful reaction, a $7 \mu \mathrm{l}$ sample from each reaction was then run via electrophoresis through a $2 \%$ agarose gel with ethidium bromide and visualized using ultraviolet (UV) light.

The four PCR products amplified by the universal DNA primers were purified using a QIAGEN QIAquick ${ }^{\circ}$ PCR purification kit according to the manufacturers protocol and sequenced in both forward and reverse directions on an ABI 377 automated sequencer (Applied Biosystems) using the Big Dye v. 3 sequencing kit.

PCR-RFLP diagnostic test to detect ace 1 mutation were carried out on the extracted DNA from the nine study sites. In the PCR assay, $3 \mu \mathrm{l}$ of genomic DNA was amplified with the primers "Moustidir1" and "Moustrev1" (Table 1) described by Weill et al. [13]. PCR was conducted in $25 \mu \mathrm{l}$ volumes containing $1 \times$ PCR buffer containing $1.5 \mathrm{mM} \mathrm{MgCl}, 0.2 \mathrm{mM}$ of each dNTP, $3.1 \mu \mathrm{l}$ of each of the primers, one unit of Taq polymerase (HotstarTaq: Qiagen ${ }^{\circ}$. The PCR conditions included an initial denaturation step at $95^{\circ} \mathrm{C}$ for $15 \mathrm{~min}$ followed by thirty five cycles of $94^{\circ} \mathrm{C}$ for $30 \mathrm{~s}, 54^{\circ} \mathrm{C}$ for $30 \mathrm{~s}$, and $72^{\circ} \mathrm{C}$ for $30 \mathrm{~s}$, and a final extension at $72^{\circ} \mathrm{C}$ for $5 \mathrm{~min}$.

Fifteen $\mu \mathrm{l}$ of the PCR product were digested with 5 units of Alu1 restriction enzyme in the final volume of $20 \mu \mathrm{l}$ and incubated at $37^{\circ} \mathrm{C}$ for $16 \mathrm{~h}$. The restriction products were fractionated on a $2 \%$ agarose gel and visualised by ethidium bromide staining under UV light.

\section{Statistical analysis}

Percentage mortality was calculated from the results of the bioassay. Percentage mortalities from different land use and ecological zones were compared using KruskalWallis test whereas difference in mortalities between the two classes of insecticides and seasons were compared using Mann Whitney test. Study sites were categorized into large urban area (metropolitan area with several sub-metro and human population more than one million) and small urban area (a metropolitan or municipal area with human population less than one million) as well as percentage mortality into resistant (mortality less than 98\%) and susceptible (mortality more than 98\%) based on WHO [14] criteria. Pearson's Chi-square and correlation test was used to determine the association between percentage mortality and enzyme levels or resistance status and urban size. Results from the esterase assays were compared between study sites with ANOVA (Analysis of Variance) and post hoc test using Fisher's Least Significant Difference. All the tests were done with SPSS $^{\circ}$ (version 20). Phylogenetic tree was constructed using Mega 6 software from aligned DNA sequences of mitochondrial cytochrome c oxidase (CO1) gene using 500 boot-straps.

\section{Results and discussion}

\section{Distribution of Culex species}

Culex quinquefasciatus was generally expected due to the breeding habitat in which the mosquitoes were collected. Nevertheless, PCR diagnostic assay confirms $C$. quinquefasciatus in only Accra and Kumasi. Besides $C$. quinquefasciatus, no member of the $C$. pipiens complex was found. Data from mitochondrial COI gene sequence did not match $100 \%$ with any existing COI sequence in GeneBank. The phylogenetic analysis (Figure 2) indicated that the unidentified Culex species could be made up of two or more different species. From the branches of the phylogenetic tree, it could be inferred that Culex species from Bolgatanga and Cape Coast were either $C$. decens or closely related to it whereas Culex species from Techiman and Sekondi were closely related to $C$. fuscocephala or C. perexiguus. The genetic resemblance of the Culex species from Techiman and Sekondi to $C$. fuscocephala and $C$. perexiguus was unexpected since such species have not been reported in Ghana before. Further studies, combining morphology and molecular information are needed to identify these species. C. fuscocephala and C. perexiguus are mostly distributed in South East Asia and the Mediterranean countries respectively (Walter Reed Biosystematics Unit, www.wrbu.org).

PCR diagnostic assay using primers designed from mitochondrial COI gene sequence of $C$. decens confirmed $C$. decens in some of the study sites (Table 2; Figure 3). This is not surprising since $C$. decens is a widely distributed 


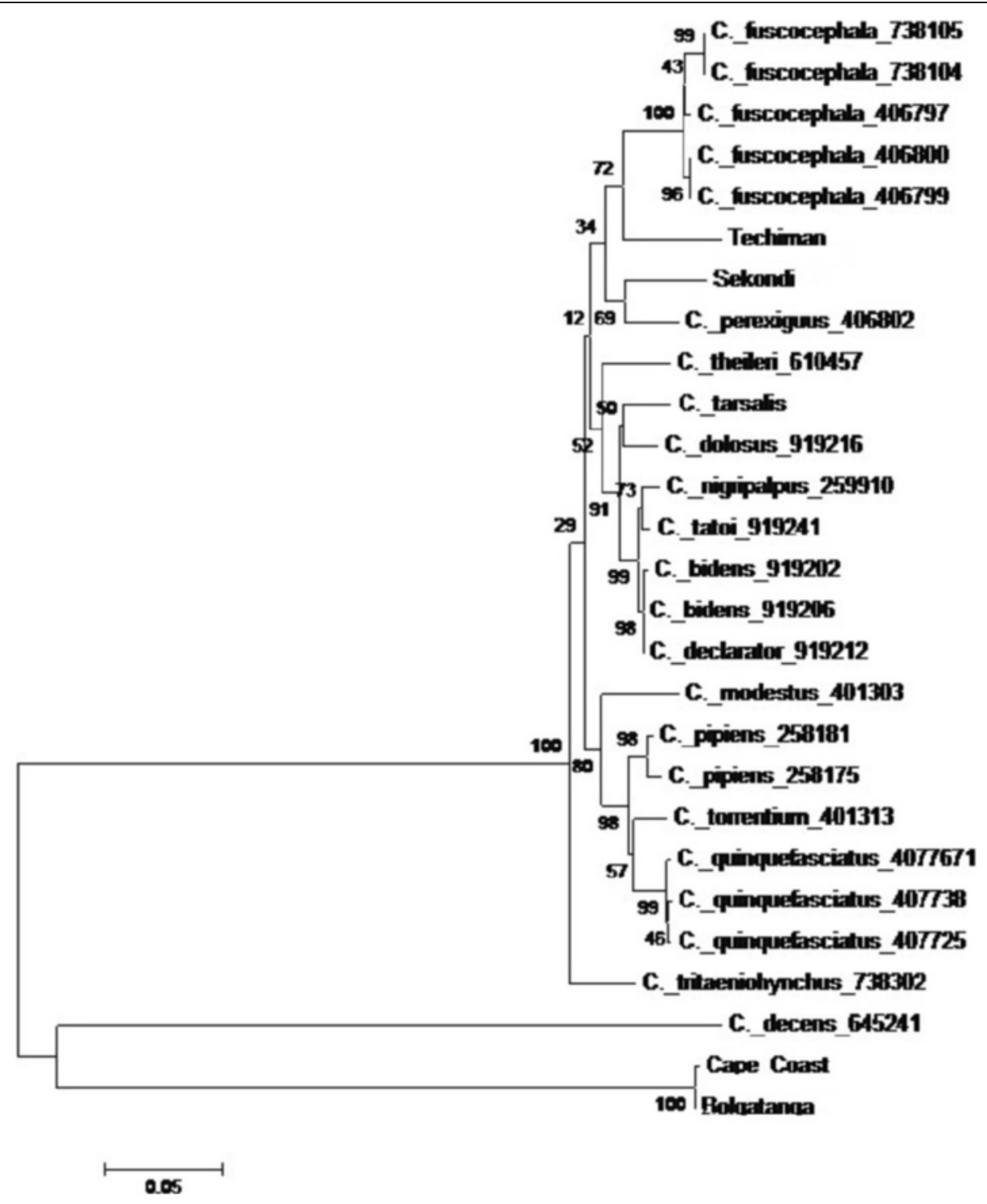

Figure 2 Phylogenetic tree constructed from aligned DNA sequences of mitochondrial cytochrome c oxidase (CO1) gene using 500 boot-straps with Mega 6 software. Techiman, Sekondi, Cape Coast and Bolgatanga are the samples collected in this study.

species in Ghana $[15,16]$; however their presence in polluted breeding habitats are not well known. The collection of $C$. decens in polluted waters is in agreement with Opoku and colleagues [16], who found $C$. decens occurring sympatrically with $C$. quinquefasciatus in polluted habitats in Accra.

Besides C. quinquefasciatus and C. decens, existence of other Culex species in the study sites is possible but the result from this study was unable to identify or confirm the identity of such species. There is a need for further studies on the diversity and habitat ecology of Culex species in Ghana. Also the development of molecular tools to identify them is vital since existing molecular tools for the identification of Culex species mostly target members of the C. pipiens complex. With further evaluation, the primers 'cddir and cdrev' could be useful molecular tools in identifying $C$. decens.

\section{Insecticide susceptibility assay}

Culex species from the study populations were susceptible to organophosphate (malathion, fenitrothion). Also, the level of carbamate (propoxur, bendiocarb) resistance was generally very low (Table 3; Figure 4). In total the carbamate-induced percentage mortality $( \pm$ SD) was $94.1 \% \pm 15.4$ whereas mortality caused by organophosphate was $99.5 \% \pm 2.2$ and the difference between the two mortalities was significant (Mann Whitney U: $\mathrm{p}<0.05$ ). Resistance to carbamate was only found in C. quinquefasciatus populations from Accra and Kumasi (large urban areas). Complete susceptibility of Culex species in Ghana 
Table 2 Distribution of ace 1 mutation (G119S) in Culex species from different urban areas in Ghana

\begin{tabular}{|c|c|c|c|c|c|c|}
\hline \multirow[t]{2}{*}{ Study sites } & \multicolumn{2}{|c|}{ Culex species } & \multicolumn{4}{|c|}{ ace 1 mutation } \\
\hline & C.q & C.d & SS & RS & $\mathbf{R R}$ & $F(R)$ \\
\hline Accra & 25 & 0 & $48 \%(12)$ & $40 \%(10)$ & $12 \%(3)$ & 0.32 \\
\hline Cape Coast & 0 & 10 & $100 \%(20)$ & $0 \%(0)$ & $0 \%(0)$ & 0 \\
\hline Kumasi & 16 & 0 & $81.3 \%(13)$ & $12.5(2)$ & $6.2 \%(1)$ & 0.13 \\
\hline Sunyani & 0 & 10 & $36.4 \%(4)$ & $45.5 \%(5)$ & $18.2 \%(2)$ & 0.41 \\
\hline Techiman & 0 & 5 & $80 \%(4)$ & $20 \%(1)$ & $0 \%(0)$ & 0.1 \\
\hline
\end{tabular}

Value in bracket represents sample size. C.q-Culex quinquefasciatus, C.d - Culex decens, SS - homozygote susceptible, RS - heterozygote resistant, $R R$ - homozygote resistant, $F(R)$ - frequency of resistant allele.

to organophosphate is good for vector control and resistance management. Although, the level of resistance to carbamate observed in this study may not have any serious implication on vector control, there is a need for constant monitoring and resistance surveillance to prevent resistance to these insecticides rising to a level that could affect insecticide resistance management strategies in the country. Environmental variables such as ecology, seasons and land use settings were marginally or non-significantly associated with carbamate and organophosphate resistance (Table 3). Culex species in Ghana and most West African countries are not epidemiologically important but many households spent a considerable amount of money and resources to prevent their nuisance $[17,18]$. Furthermore, the influence of Culex species on the use of insecticide treated net has been highlighted by several studies $[19,20]$. These reasons emphasise the importance of controlling and monitoring insecticide resistance in Culex species.

\section{Multiple insecticide resistance mechanisms}

Overall mean absorbance of $\alpha$-esterase was $0.448 \pm 0.12$, $\beta$-esterase, $0.807 \pm 0.22$ and oxidase, $0.152 \pm 0.08$ (Figure 5). Absorbance of all the three enzymes tested was higher in C. quinquefasciatus populations from Accra and Kumasi than the other Culex species. A strong negative correlation was observed between percentage mortality from the bioassay and mean absorbance of $\beta$-esterase (Pearson $\mathrm{r}=-0.841, \mathrm{p}=0.004)$. However, such significant association was not observed between percentage mortality and $\alpha$ esterase (Pearson $r=-0.45, p=0.22$ ) or oxidase (Pearson $\mathrm{r}=0.131, \mathrm{p}=0.738)$. This may suggest the involvement of enzyme activity particularly esterases in the resistance of C. quinquefasciatus to carbamate insecticides. Enhanced levels or modified activities of esterases and other detoxifying enzymes have been reported to prevent some insecticides from reaching their site of action [21]. Meanwhile, several studies have shown close association between organophosphate and carbamate resistance and high levels of esterases [22,23].

In mosquitoes, insensitive acetyl cholinesterase (AChE) is another common resistance mechanism to organophosphate

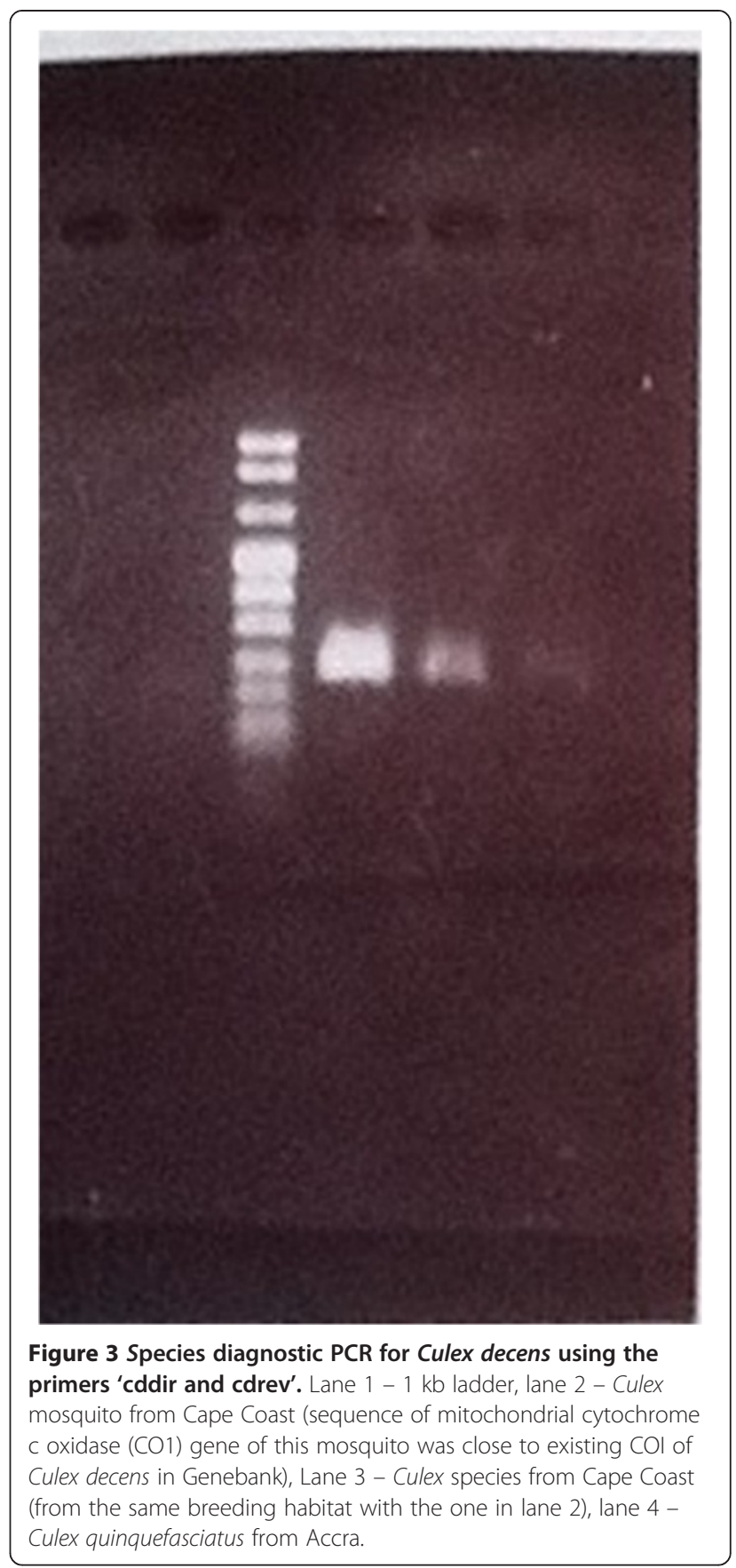

and carbamate insecticides [24]. A single mutation (G119S of the ace 1 gene) is responsible for AChE insensitivity to the two classes of insecticides [13]. The PCR diagnostic assay that was performed in the present study detected the ace 1 mutation (G119S) in some of the mosquito populations (Table 2) especially in C. quinquefasciatus. Also, ace 1 mutation was detected in $C$. decens; however, the frequency of the mutation should be interpreted with caution owing to the small sample size. Approximately equal numbers of mosquitoes (about 20 mosquitoes) from each 
Table 3 Percentage mortality $(95 \% \mathrm{Cl})$ of Culex species to organophosphate and carbamate insecticides and different environmental factors associated with it

\begin{tabular}{|c|c|c|c|c|c|}
\hline \multirow{2}{*}{\multicolumn{2}{|c|}{ Environmental factors }} & \multicolumn{4}{|c|}{ Mean mortality (\%) } \\
\hline & & \multicolumn{2}{|l|}{ Carbamate } & \multicolumn{2}{|c|}{ Organophosphate } \\
\hline & & Bendiocarb $^{*}$ & Propoxur ${ }^{*}$ & Fenitrothion $^{*}$ & Malathion $^{*}$ \\
\hline \multirow[t]{6}{*}{ Land use } & Residential & $87^{a}$ & $93^{a}$ & $99^{\mathrm{a}}$ & $99^{\mathrm{a}}$ \\
\hline & & $(78-95)$ & $(86-99)$ & $(98-100)$ & $(98-100)$ \\
\hline & Urban farm & $98^{\mathrm{a}}$ & $99^{a}$ & $99^{a}$ & $100^{b}$ \\
\hline & & $(95-101)$ & $(99-101)$ & $(99-100)$ & $(100-100)$ \\
\hline & Swampy & $98^{\mathrm{a}}$ & $97^{a}$ & $99^{\mathrm{a}}$ & $100^{b}$ \\
\hline & & $(94-101)$ & $(94-100)$ & $(99-100)$ & $(100-100)$ \\
\hline \multirow[t]{4}{*}{ Season } & Rainy & $89^{a}$ & $96^{a}$ & $99^{\mathrm{a}}$ & $99^{a}$ \\
\hline & & $(80-97)$ & (93-99) & $(98-100)$ & $(98-100)$ \\
\hline & Dry & $95.7^{\mathrm{a}}$ & $96^{\mathrm{a}}$ & $99^{a}$ & $100^{\mathrm{a}}$ \\
\hline & & (92-99) & $(90-101)$ & $(99-100)$ & $(99-100)$ \\
\hline \multirow[t]{6}{*}{ Ecology } & Coastal savannah & $94^{a, b}$ & $97^{a, b}$ & $99^{\mathrm{a}}$ & $100^{\mathrm{a}}$ \\
\hline & & $(89-100)$ & $(95-100)$ & $(99-100)$ & $(99-100)$ \\
\hline & Forest & $88^{b}$ & $93^{\mathrm{b}}$ & $99^{\mathrm{a}}$ & $99^{\mathrm{a}}$ \\
\hline & & $(80-97)$ & (86-99) & $(98-100)$ & $(98-100)$ \\
\hline & Guinea savannah & $100^{\mathrm{a}}$ & $100^{a}$ & $100^{a}$ & $100^{a}$ \\
\hline & & $(100-100)$ & $(100-100)$ & $(100-100)$ & $(100-100)$ \\
\hline
\end{tabular}

*In each insecticide, values in columns (environmental factors) sharing same letter are not significantly different.

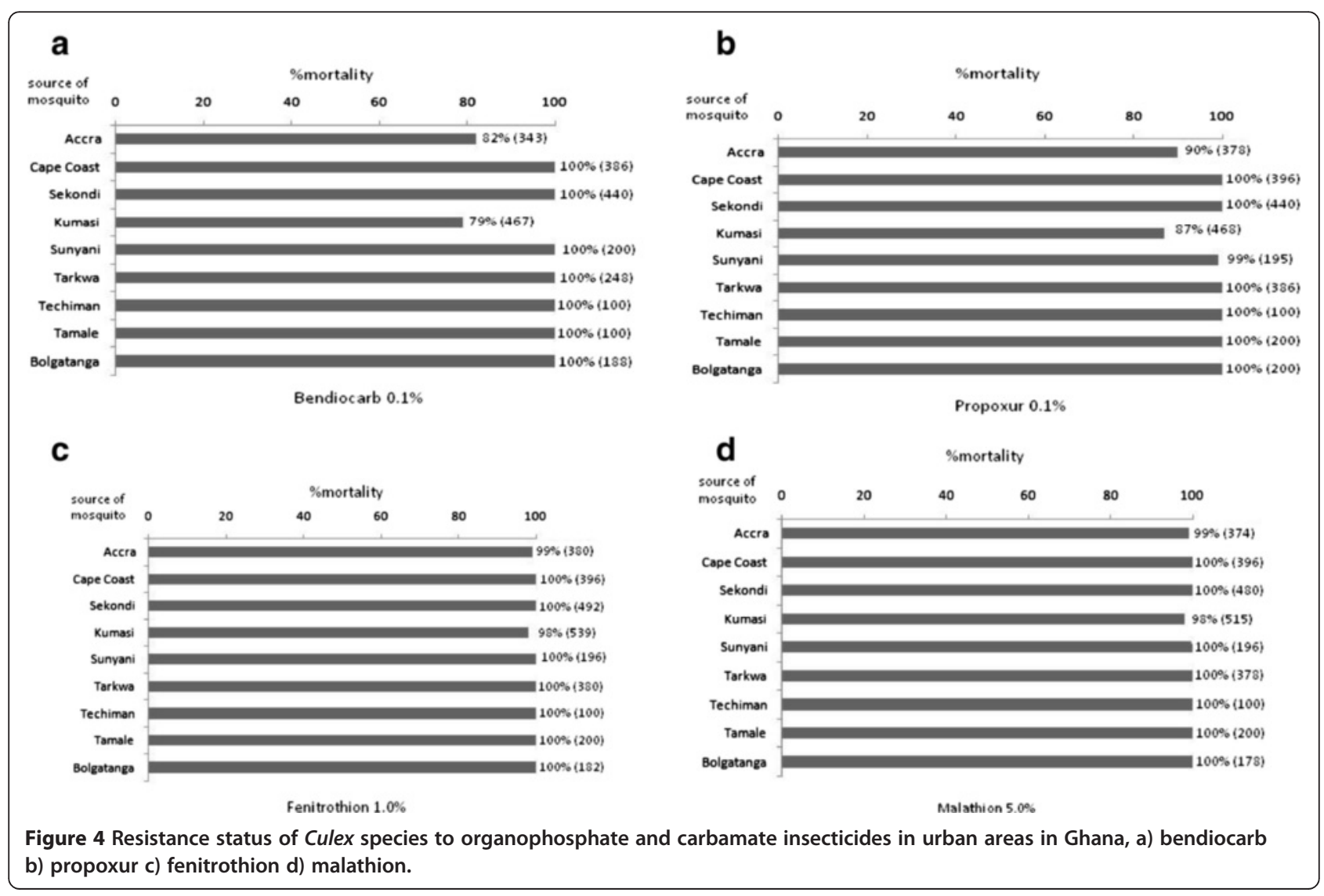




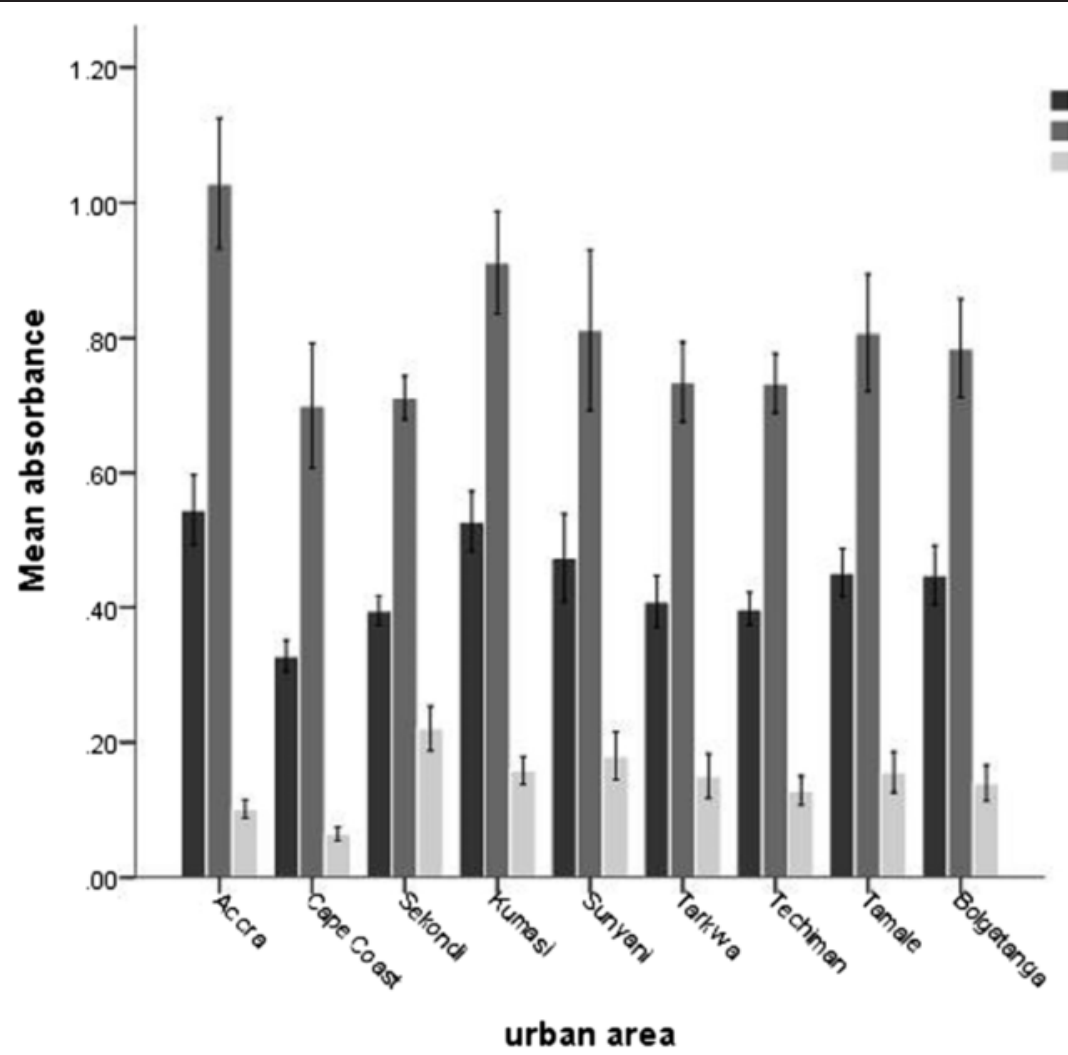

Figure 5 Mean absorbance (optic density) of a-esterase (esterase A), $\beta$-esterase (esterase B) and mixed function oxidase of Culex species from different urban areas in Ghana. (Error bar: 95\% Cl).

site were used but most study sites failed to produce results (DNA failed to amplify) with the exception of mosquitoes from Accra and Kumasi. Since this method [13] was originally designed to detect ace 1 mutation in Anopheles species and C. pipiens complex to which C. quinquefasciatus belongs, it is possible that the method is not sensitive enough for other Culex species particularly those found in this study. This may partly explain why most of the DNAs that were not from C. quinqefasciatus failed to produce results. Within the two C. quinquefasciatus populations, the distribution of the ace 1 genotypes did not differ from the Hardy-Weinberg equilibrium $(P>$ 0.05, Table 2).

Despite ace 1 mutations being reported to provide cross resistance to organophosphate and carbamate [25], the resistance level greatly varied between the two classes of insecticides. However, some studies have suggested that ace 1 mutations have a greater impact on carbamate than organophosphate resistance $[20,26]$. The reason for this is unclear at this time.

\section{Impact of urbanization on insecticide resistance}

The distribution of Culex species in this study appears to be influenced by the degree of urbanization. C. quinquefasciatus was found in the populous and most urbanized areas in Ghana whereas $C$. decens and other unidentified Culex species were found in relatively small urban areas. Although the level of pollution was not quantified in the breeding sites, it was nevertheless observed that breeding sites where mosquitoes were collected were more polluted in Accra and Kumasi than those in other urban areas (Figure 6a-d). It was therefore not surprising that $C$. quinquefasciatus was found in these areas since C. quinquefasciatus are most common in polluted heavily urbanized sites. The results also showed that other Culex species such as $C$. decens are also breeding in polluted water bodies in urban areas in Ghana.

Resistance to carbamate were observed in C. quinquefasciatus populations from Accra and Kumasi (Table 3). In addition, high levels of esterases and ace 1 mutations (Table 2) were found in the same population. This indicates a higher insecticide selection pressure in Accra and Kumasi (large urban areas) than the rest of the study sites (small urban areas). There are strong arguments in favour of agricultural and domestic use of insecticides as the major cause of resistance in urban areas [27]. Yet, despite the use of organophosphate in urban farms, mosquitoes collected from those areas were susceptible to the insecticides. Additionally, the use of carbamate and organophosphate for malaria control or 


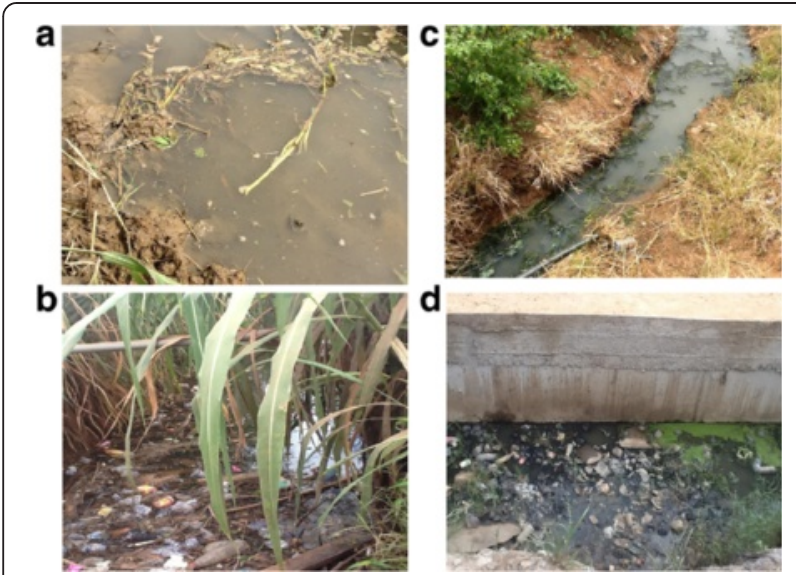

Figure 6 a-d Polluted breeding habitats where mosquito larvae were collected - a) Tarkwa, b) Sunyani, c) Kumasi, d) Accra.

domestic use of these insecticides for mosquito control is limited. Therefore, agricultural and domestic use of insecticides cannot fully explain the cause of resistance in the present study.

Another cause of resistance in mosquitoes which until recently has received little attention is the presence of pollutants in breeding habitats of mosquitoes. Exposure of mosquitoes to common urban pollutants has been shown to increase mosquito tolerance to insecticides in some studies $[28,29]$. We suspect pollutants found in breeding habitats to have played a role in resistance of C. quinquefasciatus to carbamate in this study. However, the result from the study cannot confirm this hypothesis. In a related study, Chandre and colleagues [30] were also not able to relate carbamate and organophosphate resistance in C. quinquefasciatus in Ivory Coast and Burkina Faso to the use of agricultural pesticides but rather implicated domestic use of insecticides to be associated with corresponding resistances. Similarly, Anopheles species that were sampled from an urban vegetable farm in Accra were susceptible to organophosphate, though several organophosphate insecticides were detected in the water body in which the mosquito was breeding [31]. On the contrary, Essandoh and colleagues [20] implicated agricultural use of pesticides as a cause of carbamate and organophosphate in Anopheles species from peri-urban agricultural area near Accra.

The presence of $C$. decens in polluted breeding sites, which is not known to breed in such habitats, coupled with various reports that have observed A. gambiae, a major malaria vector, also breeding in polluted habitats $[32,33]$ reinforces the need to take a critical look at the numerous polluted breeding sites scattered in the country. Both solid and liquid waste are poorly managed in urban areas in Ghana as well as many African countries and what enters into gutters or water bodies from commercial and domestic activities is not much regulated. This presents a situation where apart from pesticides officially sanctioned for public use, mosquitoes could also be exposed to unknown chemicals or insecticides in polluted breeding habitats, which can select for resistance mechanisms that can confer high level of resistance to new insecticides that officially have not been recognized to be used in the country.

\section{Conclusions}

The study found low prevalence of resistance to carbamate and organophosphate insecticides among Culex species from Ghana. Due to low levels of resistance to the insecticides, resistance management strategies comprising the use of organophosphate and carbamate may be successful against pyrethroid-resistant Culex species in Ghana. However, such strategies must be carried out with caution since populations with ace 1 mutations and high levels of esterases, which can confer high resistance to these classes of insecticides, already exist.

This is the first study in Ghana showing evidence of the existence of multiple insecticide resistance mechanisms in C. quinquefasciatus to carbamates and organophosphates. With the existence of populations with multiple resistance mechanisms, it is important to monitor activities or behaviours that have the potential to select for resistance populations. Besides agriculture and domestic use of insecticides, urban pollutants found in mosquito breeding habitats have also been implicated as a cause of resistance. With the expansion of agricultural activities in urban areas, the amount of pesticides used is greatly increasing. In addition, inadequate urban infrastructure, partly due to rapid population growth, leads to creation of numerous polluted habitats that are suitable for mosquito breeding. For these reasons, proper management of waste, particularly in urban areas, and effective regulation of the use of pesticides appear to be critical for managing insecticide resistance.

\section{Competing interests}

The authors declare that they have no competing interests.

\section{Authors' contributions}

AAK participated in the design and coordination of the study, carried out the field work and data collection, performed statistical analysis of the study and drafted the manuscript. BAM, GF, DB, and HR participated in the study design and contributed to the writing of the manuscript. All authors read and approved the final manuscript.

\section{Acknowledgements}

We are grateful to Kwadwo Frimpong, Selasie P. Bansah and all the staff of Noguchi Memorial Institute for Medical Research (NMIMR) who helped during the molecular and biochemical assays. We also appreciate the contribution of Eddy Odari during the molecular work. We acknowledge the Federal Ministry for Economic Cooperation and Development (BMZ), the German Academic Exchange Services (DAAD) together with its ExceedProgramme for the offer of scholarship to AAK. We also appreciate the Parasitology Unit of NMIMR and Department of Entomology and Wildlife, University of Cape Coast for their contribution to the project. We are also grateful to the anonymous reviewers for their constructive criticism. 


\section{Author details}

${ }^{1}$ Center for International Health, Department of Infectious Diseases and Tropical Medicine, Ludwig-Maximilians-Universität Munich, Munich, Germany. ${ }^{2}$ Department of Entomology and Wildlife, School of Biological Sciences, University of Cape Coast, Cape Coast, Ghana. ${ }^{3}$ Noguchi Memorial Institute for Medical Research, University of Ghana, P.O. Box LG 581, Legon, Ghana. ${ }^{4}$ Bayerisches Landesamt für Gesundheit und Lebensmittelsicherheit (LGL), Veterinärstraße 2, Oberschleißheim 85762, Germany.

Received: 30 May 2014 Accepted: 22 December 2014

Published online: 08 January 2015

\section{References}

1. WHO. World Malaria Report. 2013. (http://www.who.int/malaria/publications). Accessed: January, 2014

2. WHO. Global action plan for insecticide resistance management in malaria vector (GPIRM). Geneva, Switzerland: World Health Organization; 2012.

3. IRAC. Prevention and Management of Insecticide Resistance in Vectors of Public Health Importance. 2nd ed. A manual produced by: Insecticide Resistance Action Committee (IRAC); 2011.

4. Oxborough RM, Kitau J, Jones R, Feston E, Matowo J, Mosha FW, et al. Long-lasting control of Anopheles arabiensis by a single spray application of micro-encapsulated pirimiphos-methyl (Actellic 300 CS). Malaria J. 2014;13:37.

5. Guillet P, N'Guessan R, Darriet F, Traore-Lamizana M, Chandre E, Carnevale P. Combined pyrethroid and carbamate "two in one' treated mosquito nets: field efficacy against pyrethroid-resistant Anopheles gambiae and Culex quinquefasciatus. Med Vet Entomol. 2001;15:105-12.

6. Nkya TE, Akhouayri I, Kisinza W, David J-P. Impact of environment on mosquito response to pyrethroid insecticides: facts, evidences and prospects. Insect Biochem Mol Biol. 2013:43:407-16.

7. Hunt RH, Fuseini G, Knowles S, Stiles-Ocran J, Verster R, Kaiser ML, et al. Insecticide resistance in malaria vector mosquitoes at four localities in Ghana. West Afr Parasit Vec. 2011;4:107.

8. Essandoh J, Yawson AE, Weetman D. Acetylcholinesterase (Ace1) target site mutation 1195 is strongly diagnostic of carbamate and organophosphate resistance in Anopheles gambiae s.s and Anopheles coluzzii across southern Ghana. Malaria J. 2014;12:404

9. Okoye PN, Brooke BD, Koekemoer LL, Hunt RH, Coetzee M. Characterisation of DDT, pyrethroid and carbamate resistance in Anopheles funestus from Obuasi, Ghana. Trans R Soc Trop Med Hyg. 2008;102:591-8.

10. Hemingway J. Techniques to Detect Insecticide Resistance Mechanisms (Field and Laboratory Manual). WHO/CDS/CPC/MAL/98.6. Geneva, Switzerland: World Health Organization; 1998.

11. Smith JL, Fonseca DM. Rapid assays for identification of members of the Culex (Culex) pipiens complex, their hybrids, and other sibling species (Diptera: culicidae). Am J Trop Med Hyg. 2004;70:339-45.

12. Folmer $\mathrm{O}$, Black $M$, Hoeh W, Lutz R, Vrijenhoek R. DNA primers for amplification of mitochondrial cytochrome c oxidase subunit I from diverse metazoan invertebrates. Mol Mar Biol Biotechnol. 1994;3:294-9.

13. Weill M, Malcolm C, Chandre F, Mogensen K, Berthomieu A, Marquine M, et al. The unique mutation in Ace1 giving high insecticide resistance is easily detectable in mosquito vectors. Insect Mol Biol. 2004;13:1-7.

14. WHO. Test procedures for insecticide resistance monitoring in malaria vector mosquitoes. Geneva, Switzerland: WHO Document Production Services; 2013

15. Opoku AA, Ansa-Asare OD, Amoako J. The occurrences and habitat characteristics of mosquitoes in Accra, Ghana. West Afr J Appl Ecol. 2007;11:81-6.

16. Macfie JWS, Ingram A. The Early Stages of West African Mosquitos. V.-Culex decens, Theo. and Culex invidiosus, Theo. 1920 Bull Entomol Res 1920; 11: 105-12.

17. Boakye DA, Adasi K, Appawu M, Brown CA, Wilson MD. Patterns of household insecticide use and pyrethroid resistance in Anopheles gambiae Sensu Stricto (Diptera: Culicidae) within the Accra Metropolis of Ghana. Afr Entomol. 2009;17:125-30.

18. Kudom AA, Mensah BA, Nunoo J. Assessment of anti-mosquito measures in households and resistance status of Culex species in urban areas in southern Ghana: implications for the sustainability of ITN use. Asian Pac J Trop Med. 2013;6(11):859-64.

19. Alaii JA, Borne WVD, Kachur SP, Shelley K, Mwenesi H, Vulule JM, et al. Community reactions to the introduction of permethrin-treated bed nets for malaria control during a randomized controlled trial in Western Kenya. Am J Trop Med Hyg. 2003;68 Suppl 4:128-36.

20. Asidi AN, N'Guessan R, Koffi AA, Curtis CF, Hougard JM, Chandre F, et al. Experimental hut evaluation of bed nets treated with an organophosphate (chlorpyrifos methyl) or a pyrethroid (lambdacyhalothrin) alone and in combination against insecticide-resistant Anopheles gambiae and Culex quinquefasciatus mosquitoes. Malar J. 2005;4:25.

21. Hemmingway J, Ranson $\mathrm{H}$. Insecticide resistance in insect vectors of human disease. Annu Rev Entomol. 2000;45:371-91.

22. Georghiou GP, Pasteur N. Organophosphate resistance and esterase pattern in a natural population of the southern house mosquito from California. J Econ Entomol. 1980;73:489-92.

23. Alout H, Labbe P, Pasteur N, Weill M. High incidence of Ace1 duplicated haplotypes in resistant Culex pipiens mosquitoes from Algeria. Insect Biochem Mol Biol. 2011;41:29-35.

24. Fournier D, Mutero A. Modification of acetylcholinesterase as a mechanism of resistance to insecticides. Comp Biochem Physiol C Pharmacol Toxicol Endocrinol. 1994;108:19-31.

25. Alout H, Djogbénou L, Berticat C, Chandre F, Weill M. Comparison of Anopheles gambiae and Culex pipiens acetycholinesterase 1 biochemical properties. Comp Biochem Physiol B. 2008;150:271-7.

26. Djogbénou L, Weill M, Hougard JM, Raymond M, Akogbeto M, Chandre F. Characterization of insensitive acetylcholinesterase (Ace1R) in Anopheles gambiae (Diptera: Culicidae): resistance levels and dominance. J Med Entomol. 2007:44:805-10

27. Diabate A, Baldet T, Chandre F, Akogbeto M, Guiquemde RT, Darriet F, et al. The role of agricultural use of insecticides in resistance to pyrethroids in Anopheles gambiae s.l. in Burkina Faso. Am J Trop Med Hyg. 2002;67:617-22.

28. Poupardin R, Reynaud S, Strode C, Ranson H, Vontas J, David JP. Cross induction of detoxification genes by environmental xenobiotics and insecticides in the mosquito Aedes aegypti: impact on larval tolerance to chemical insecticides. Insect Biochem Mol Biol. 2008;38:540e551.

29. Riaz MA, Poupardin R, Reynaud S, Strode C, Ranson H, David JP. Impact of glyphosate and benzo[a]pyrene on the tolerance of mosquito larvae to chemical insecticides: role of detoxification genes in response to xenobiotics. Aquat Toxicol. 2009;93:61e69.

30. Chandre F, Darriet F, Doannio JMC, Riviere F, Nicole Pasteur N, Guillet P. Distribution of organophosphate and carbamate resistance in Culex pipiens quinquefasciatus (Diptera: Culicidae) in West Africa. J Med Entomol. 1997;34:664-71.

31. Achonduh OA, Gbewonyo WSK WSK, Boakye DA, Wilson MD. Susceptibility Status of Anopheles gambiae s.l. (Diptera: Culicidae) from cabbage growing areas associated with pyrethroid and organophosphate use in Accra, Ghana. West Afr J Appl Ecol. 2008;12:1.

32. Kudom AA, Mensah BA, Agyeman TK. Characterization of mosquito larval habitats and assessment of insecticide-resistance status of Anopheles gambiae sensu lato in urban areas in south western Ghana. J Vector Ecol. 2012;37(1):77-82

33. Keating J, Macintyre K, Mbogo C, Githeko A, Regens JL, Swalm C, et al. A geographic sampling strategy for studying relationships between human activity and malaria vectors in urban Africa. Am J Trop Med Hyg. 2003;68:357-65.

\section{Submit your next manuscript to BioMed Central and take full advantage of:}

- Convenient online submission

- Thorough peer review

- No space constraints or color figure charges

- Immediate publication on acceptance

- Inclusion in PubMed, CAS, Scopus and Google Scholar

- Research which is freely available for redistribution 